\title{
Towards Controlling Photochemical Reactivity in Small Polyatomic Molecules in Solution: Difluorodiiodomethane
}

\author{
P. Z. El-Khoury ${ }^{1}$, S. K. Pal ${ }^{2}$, A. S. Mereshchenko ${ }^{3}$, A. N. Tarnovsky ${ }^{3}$ \\ ${ }^{1}$ Department of Chemistry, University of California, Irvine, California 92697, USA \\ ${ }^{2}$ School of Basic Sciences, Indian Institute of Technology, Mandi, Himachal Pradesh 175 001, India \\ ${ }^{3}$ Department of Chemistry, Center for Photochemical Sciences, Bowling Green State University, \\ Bowling Green, $\mathrm{OH}$, USA
}

\begin{abstract}
Ultrafast transient absorption and tools of computational photochemistry monitor the efficient formation of molecular iodine from difluorodiiodomethane promoted to the lowest excited state in inert solvents: this requires significantly larger photon energies in the gas-phase.
\end{abstract}

One of the main challenges in the field of photochemical reaction dynamics is to understand the effect of initial conditions on the outcome of ultrafast molecular transformations. In solution or condensed phases, the bath plays an intimate, time-dependent role in the entire reaction process. This adds further complexity to the reaction dynamics which involve multiple potential energy surfaces. A topic of significant interest is two- $v s$ three-body photodissociation in which the excited state species yields two or three products, [1,2]. The latter decay may occur simultaneously, in a concerted fashion, or sequentially, as a result of vibration energy redistribution in hot radicals. $\mathrm{CF}_{2} \mathrm{I}_{2}$ follows several dissociation channels in the gas-phase, [3-5], this complexity constituting the major driving force behind selecting this molecule as a target system for condense-phase ultrafast transient absorption studies.

In the gas phase, excitation of $\mathrm{CF}_{2} \mathrm{I}_{2}$ in the $351-337 \mathrm{~nm}$ range exclusively causes direct two-body decay: $\mathrm{CF}_{2} \mathrm{I}_{2} \rightarrow \mathrm{CF}_{2} \mathrm{I} \cdot+\mathrm{I} \cdot$, ref. [3]. Excitation at $\lambda<266 \mathrm{~nm}$ leads to a concerted decay: $\mathrm{CF}_{2} \mathrm{I}_{2} \rightarrow: \mathrm{CF}_{2}+\mathrm{I} \cdot+\mathrm{I} \cdot$. In the intermediate range, two-body decay is followed by $\mathrm{C}-\mathrm{I}$ bond dissociation in vibrationally hot radicals, [4,5]. Only upon 193-nm $(6.5 \mathrm{eV})$ excitation of $\mathrm{CF}_{2} \mathrm{I}_{2}$ is molecular iodine elimination observed, [6].

Following 350-nm excitation of $\mathrm{CF}_{2} \mathrm{I}_{2}$ in $n$-hexane, a 75-fs decay of $\Delta A$ signals in short-time visible/near-IR transient absorption spectra is assigned to the lowest excited-state depopulation due to dissociation. At $10 \mathrm{ps}$, the evolution of visible/near-IR transient absorption $\Delta A$ is dominated by vibrationally excited $\mathrm{I}_{2}$, which terminates at $\sim 200$ ps in $n-\mathrm{C}_{6} \mathrm{H}_{14}$ and $\sim 500$ ps in $\mathrm{CCl}_{4}$, with the formation of a $\sim 520$-nm band characteristic of cold $\mathrm{I}_{2}$, Fig. 1 .

This is an Open Access article distributed under the terms of the Creative Commons Attribution License 2.0, which permits unrestricted use, distribution, and reproduction in any medium, provided the original work is properly cited. 

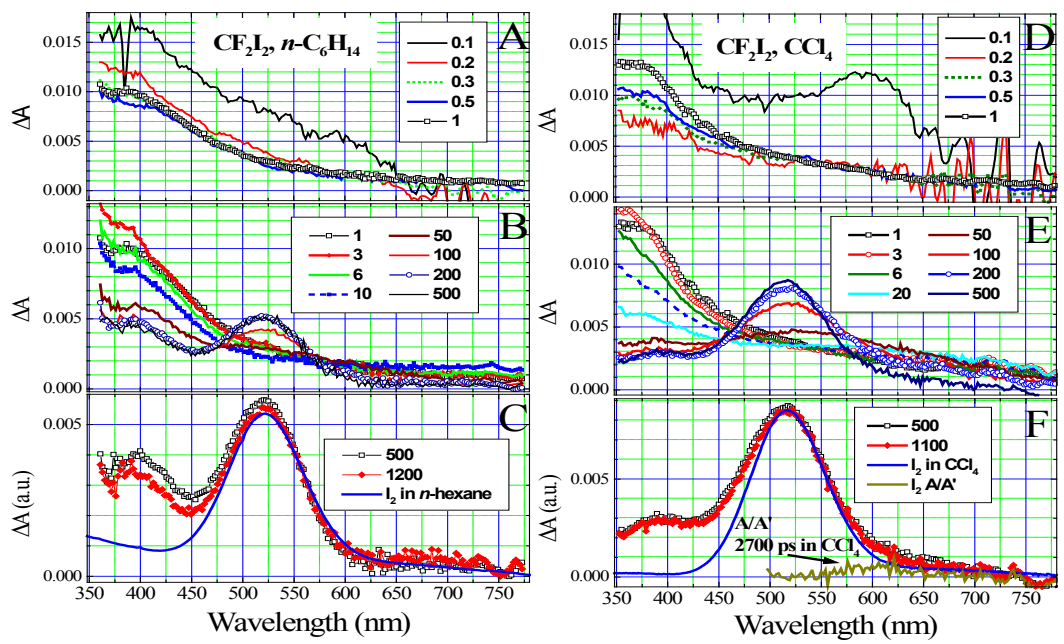

Fig. 1. The transient absorption spectra (symbols) for $\mathrm{CF}_{2} \mathrm{I}_{2}$ in $n-\mathrm{C}_{6} \mathrm{H}_{14}(\mathrm{~A}-\mathrm{B})$ and $\mathrm{CCl}_{4}$ (D-F) after $350-\mathrm{nm}$, 100 -fs excitation. Time delays (ps) are given in the insets. In $\mathrm{CCl}_{4}$, a small fraction $(6 \%)$ of the formed $\mathrm{I}_{2}$ molecules is trapped in the long-lived A/A' excited states. Steady-state absorption spectra of $\mathrm{I}_{2}$ are shown for comparison.

One $\mathrm{I}_{2}$ molecule is produced per electronically excited $\mathrm{CF}_{2} \mathrm{I}_{2} *$ on the basis of the absence of the time-dependence of $\Delta \mathrm{A}$ signals on $\mathrm{CF}_{2} \mathrm{I}_{2}$ concentration, the linear dependence of $\mathrm{I}_{2}$ concentration on the pump energy, and the time scale observed for $\mathrm{I}_{2}$ formation. By means of benzophenone triplet state actinometry, we obtained a $32 \%(500 \mathrm{ps})$ and $66 \%(1 \mathrm{~ns})$ quantum yield for $\mathrm{I}_{2}$ formation in $n$ $\mathrm{C}_{6} \mathrm{H}_{14}$, [2] and $\mathrm{CCl}_{4}$, respectively. This is in contradiction to the gas-phase findings where the lowest excited state of $\mathrm{CF}_{2} \mathrm{I}_{2}$ accessed at about $350 \mathrm{~nm}$ dissociates to produce $\mathrm{CF}_{2} \mathrm{I} \cdot$ and $\mathrm{I} \cdot\left({ }^{2} \mathrm{P}_{3 / 2}\right)$ photofragments. The electronically excited states of $\mathrm{CF}_{2} \mathrm{I}_{2}$ in the Franck-Condon (FC) region are unaltered as evidenced by identical UV absorption spectra in the gas-phase and solution, but the resonance Raman spectra of $\mathrm{CF}_{2} \mathrm{I}_{2}$ are strongly solvent-dependent, [6]. As we observed the formation of $\mathrm{I}_{2}$ from $\mathrm{CF}_{2} \mathrm{I}_{2}$ in all $\mathrm{CH}_{3} \mathrm{OH}$, alkanes and chlorinated alkanes, we conclude that the solvent affects the dynamics after $\mathrm{CF}_{2} \mathrm{I}_{2}{ }^{*}$ leaves the $\mathrm{FC}$ region. Two possible mechanisms can be thought of: (i) a consecutive three body-decay, in which hot $\mathrm{CF}_{2} \mathrm{I}$ rapidly dissociates, and the nascent I-atoms collapse into $\mathrm{I}_{2}$, (ii) the involvement of possible precursors of $\mathrm{I}_{2}$, namely, an $\mathrm{CF}_{2} \mathrm{I}-\mathrm{I}$ intermediate, analogous to the $\mathrm{CH}_{2} \mathrm{I}-\mathrm{I}$ isomer of $\mathrm{CH}_{2} \mathrm{I}_{2}$, , [2].

To distinguish between these two reaction mechanisms, we first conducted an ab initio investigation of ground-state pathways leading to $\mathrm{I}_{2}$ elimination from $\mathrm{CF}_{2} \mathrm{I}_{2}$, [7]. Direct formation of $\mathrm{I}_{2}$ from $\mathrm{CF}_{2} \mathrm{I}_{2}$ is found to be highly endothermic, proceeding through a cyclic-skewed transition state at $2.71 \mathrm{eV}$ above $\mathrm{CF}_{2} \mathrm{I}_{2}$. However, a minimum corresponding to $\mathrm{CF}_{2} \mathrm{I}-\mathrm{I}$ is found to be at $1.08 \mathrm{eV}$ above $\mathrm{CF}_{2} \mathrm{I}_{2}$. 350-nm excitation populates the lowest excited state of $\mathrm{B}_{1}$ symmetry, which does not correlate to $\mathrm{I}_{2},[5,6], \mathrm{CF}_{2} \mathrm{I} \cdot$ and $\mathrm{I} \cdot$ being the sole photoproducts in the gas phase. In solution, the solvent cage arrests the separation of nascent photofragments, which renders the formation of the $\mathrm{CF}_{2} \mathrm{I}-\mathrm{I}$ isomer possible following excitation of $\mathrm{CF}_{2} \mathrm{I}_{2}$. The computed minimum energy path from $\mathrm{CF}_{2} \mathrm{I} \cdot \mathrm{I} \cdot \mathrm{I} \cdot$ to $\mathrm{CF}_{2} \mathrm{I}-\mathrm{I}$ is nearly barrierless, [7]. Vibrationally hot $\mathrm{CF}_{2} \mathrm{I}-\mathrm{I}$ can dissociate into : $\mathrm{CF}_{2}$ and $\mathrm{I}_{2}$ because the formation of : $\mathrm{CF}_{2}+\mathrm{I}_{2}$ from cold $\mathrm{CF}_{2} \mathrm{I}-\mathrm{I}$ is only uphill by $0.82 \mathrm{eV} v \mathrm{~s} .1 .10 \mathrm{eV}$ requiring for the production of the $\mathrm{CF}_{2} \mathrm{I} \cdot \mathrm{I} \cdot \mathrm{I}$ species. The light : $\mathrm{CF}_{2}$ fragment is thought to escape the solvent cage before the backward orientation-specific insertion reaction takes place. Second, the photochemical reaction path was modeled using CASSCF calculations following the promotion of $\mathrm{CF}_{2} \mathrm{I}_{2}$ into its lowest-lying excited singlet state, [8]. It was found that conical intersection drives the electronically excited $\mathrm{CF}_{2} \mathrm{I}_{2}$ species to the $\mathrm{CF}_{2} \mathrm{I} \cdot+\mathrm{I} \cdot$ radical pair. Third, the formation of a $\mathrm{CF}_{2} \mathrm{I}-\mathrm{I}$ intermediate was monitored through its intense $\mathrm{CF}_{2}$ stretching by means ultrafast IR absorption following 350-nm excitation of $\mathrm{CF}_{2} \mathrm{I}_{2}$ in $\mathrm{CCl}_{4}$, [9]. A delayed rise of the $\mathrm{CF}_{2}$ fundamental absorption 
places an upper limit of 400 fs for $\mathrm{C}-\mathrm{I}$ bond dissociation and primary geminate recombination, Fig. 2. The $\mathrm{CF}_{2}$ absorption weakens at about $5 \mathrm{ps}$, concurrently with the formation of $\mathrm{I}_{2}$ monitored in the visible region. According to our normal mode analysis, the isomer has a built-in vibrational energy dissipation pathway which efficiently channels one quantum deposited on the $\mathrm{CF}_{2}$ moiety into two quanta of the $v_{7}$ mode, which is best described by $\mathrm{CF}_{2}$ scissoring coupled to the "reactive" $\mathrm{C}-\mathrm{I}$ stretching.
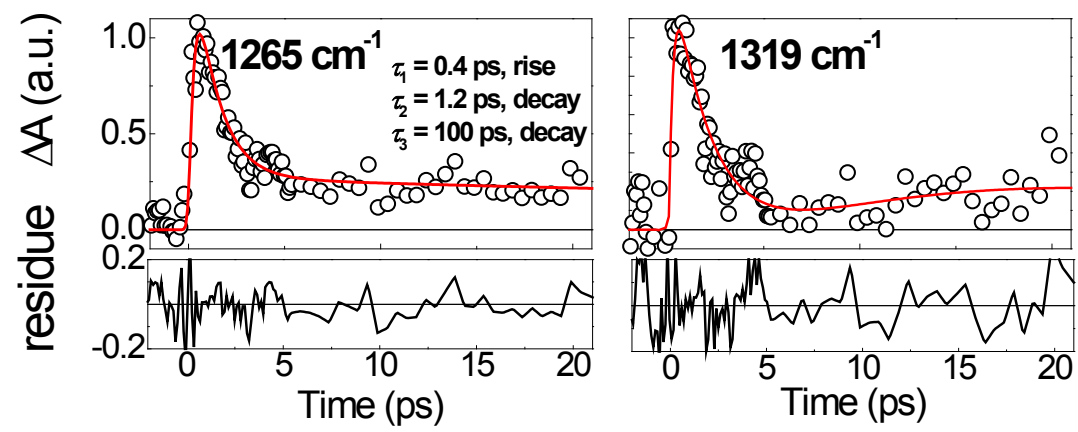

Fig. 2. $\mathrm{CF}_{2} \mathrm{I}_{2}$ in $\mathrm{CCl}_{4}$ excited at $350 \mathrm{~nm}$. The 1265 and $1319 \mathrm{~cm}^{-1}$ kinetic $\triangle A$ traces (symbols) measured at the high-energy wing of the $\mathrm{CF}_{2}$ stretching absorption band ( $v_{9}=1252 \mathrm{~cm}^{-1}$, MP2/Sadlej-pVTZ) in the $\mathrm{CF}_{2} \mathrm{I}-\mathrm{I}$ isomer. The best three-exponential fits convoluted with an instrument response function of $235 \mathrm{fs}$ (fwhm) and fit residuals are shown as lines.

In summary, the ultrafast formation of $\mathrm{I}_{2}$ from $\mathrm{CF}_{2} \mathrm{I}_{2} *$ in solution is a result of switching dissociation into molecular iodine elimination through the intermediacy of the short-lived $\mathrm{CF}_{2} \mathrm{I}-\mathrm{I}$ isomer. This reaction proceeds through a series of distinct symmetry-allowed steps rather than the symmetry-forbidden, high-energy molecular elimination reaction path which retains $\mathrm{C}_{2 \mathrm{v}}$ symmetry.

This work was supported by the NSF (CAREER CHE-0847707 award: ANT). An allocation of computer time from the Ohio Supercomputer Center is gratefully acknowledged.

\section{References}

1. C. Maul and K. H. Gericke, "Photo Induced Three Body Decay," Int. Rev. Phys. Chem. 16, 1 (1997).

2. P. Z. El-Khoury and A. N. Tarnovsky, "Ultrafast Formation of $\mathrm{I}_{2}$ Following 350-nm Photodissociation of $\mathrm{CF}_{2} \mathrm{I}_{2}$ in $n$-Hexane," Chem. Phys. Lett. 453, 160 (2008).

3. K. Bergmann, R. T. Carter, G. E. Hall, and J. R. Huber, "Resonance Enhanced Multiphoton Ionization Time-of-Flight Study of $\mathrm{CF}_{2} \mathrm{I}_{2}$ Photodissociation,” J. Chem. Phys. 109, 474 (1998).

4. [E. A. J. Wannenmacher, P. Felder, and J. R. Huber, "The Simultaneous Three-Body Dissociation of $\mathrm{CF}_{2} \mathrm{I}_{2}$," J. Chem. Phys. 95, 986 (1991).

5. G. Baum, P. Felder, and J. R. Huber, "Photofragmentation of $\mathrm{CF}_{2} \mathrm{I}_{2}$. Competition between Radical and Three-Body Dissociation,” J. Chem. Phys. 98, 1999 (1993).

6. H. A Scheld, A. Furlan, and J. R. Huber, "Formation of Molecular Iodine by Photodissociation of $\mathrm{CF}_{2} \mathrm{I}_{2}$ at $193 \mathrm{~nm}$," Chem. Phys. Lett. 326, 366 (2000).

7. X. Zheng and D. L. Phillips, Chem. Phys. Lett. "Substituents and Solvent Effects on the ShortTime A-band Photodissociation Dynamics of $\mathrm{CF}_{2} \mathrm{I}_{2}$," Chem. Phys. Lett. 313, 467 (1999).

8. [P. Z. El-Khoury, A. N. Tarnovsky, I. Schapiro, M. N. Ryazantsev, and M. Olivucci, "Structure of the Photochemical Reaction Path Populated via Promotion of $\mathrm{CF}_{2} \mathrm{I}_{2}$ into its First Excited State," J. Phys. Chem. A, 113, 10767 (2009).

9. P. Z. El-Khoury, L. George, A. Kalume, S. A. Reid, B. S. Ault, and A. N. Tarnovsky, "Characterization of iso- $\mathrm{CF}_{2} \mathrm{I}_{2}$ in Frequency and Ultrafast Time Domains," J. Chem. Phys. 132, 124501 (2010). 